\title{
O PAPEL DO ESTADO NA INCLUSÃO DE ATLETAS TRANSEXUAIS NO ESPORTE À LUZ DA TEORIA DO RECONHECIMENTO SOCIAL
}

\author{
Edinilson Donisete Machado ${ }^{1}$ \\ Marco Antonio Turatti Junior ${ }^{2}$
}

\section{RESUMO}

Considerando a ideia da inclusão, objetiva-se indicar o papel do Estado no tratamento de atletas transexuais no esporte, à luz da teoria do reconhecimento social, indicando a vulnerabilidade sofrida pelo grupo na questão de gênero e a necessidade de um diálogo interdisciplinar. Para tanto, procede-se ao método dedutivo, compreendendo tal inclusão como promoção dos direitos humanos, uma vez que o esporte é um instrumento social, pautando discussões e acarretando visibilidade ao grupo LGBT. Assim, conclui-se que a acepção coletiva dessa medida por parte do Estado é garantir o respeito da dignidade da pessoa humana, em ordem individual e coletiva.

Palavras chave: gênero e sexualidade; transexualidade; identidade; inclusão social no esporte; Axel Honneth.

\section{THE ROLE OF THE STATE IN THE INCLUSION OF TRANSEXUAL ATHLETES IN SPORTS CONSIDERING THE THEORY OF SOCIAL RECOGNITION}

\begin{abstract}
Considering the social inclusion, it aims to indicate the role of the State in treatment of transsexual athletes in sport, considering the theory of social recognition, indicating the gender-vulnerability suffered by the group and the need for an interdisciplinary dialogue. To do so, the deductive method is applied, including such inclusion as promotion of human rights, since sport is a social instrument, bringing visibility to the LGBT group. Thus, it is concluded that the collective acceptance of this measure by the State is to guarantee respect for the dignity of the human person, in a social order.
\end{abstract}

Keywords: gender and sexuality; transsexuality; identity; social inclusion in sport; Axel Honneth.

\section{INTRODUÇÃO}

\footnotetext{
${ }^{1}$ Mestrado em Direito pela Universidade Estadual Paulista Júlio de Mesquita Filho (2000) e Doutorado em Direito pela Pontifícia Universidade Católica de São Paulo (2006). Atualmente é professor titular do Centro Universitário Eurípides de Marília-UNIVEM e da Universidade Estadual Norte do Paraná, na graduação e na pós- graduação.

${ }^{2}$ Mestre em Ciência Jurídica pelo Programa de Pós Graduação em Ciência Jurídica da Universidade Estadual do Norte do Paraná. Especialista em Justiça Constitucional e Tutela Jurisdicional dos Direitos pelo curso de Alta Formação da Universidade de Pisa, na Itália, em 2013. Graduado pela Universidade Estadual do Norte do Paraná em 2015. Advogado e professor. E-mail: juniorturatti@hotmail.com.
} 
O esporte é um instrumento de manifestação social da população e amplamente difundido entre suas tantas modalidades e competições ao longo da história. Não por menos, o direito ao esporte é considerado constitucionalmente e tem status de direitos humanos, internacionalmente. Contudo, ele ainda carrega uma divisão binária de gênero que ainda polemiza e impossibilita a inclusão das pessoas transexuais (ou transgêneras): feminino $\mathrm{x}$ masculino. Hoje, a discussão de gêneros e sexualidades está muito mais ramificada na sociedade, seja pelos estudos acadêmicos, pelo movimento de militância ou a representatividade social que vem despontando. Assim, a inclusão social da pessoa trans no esporte ainda gera dúvidas sobre diferenças biológicas que essa identidade pode acarretar, e tais dúvidas refletem no cotidiano. Por isso, objetiva-se com esse trabalho indicar o papel do Estado nessa situação, para que não ocorra injustiça, e seja preservado os direitos individuais, e também da coletividade.

O presente artigo, então, demonstra a situação atual, brasileira e mundial, analisada pelo viés da teoria do reconhecimento social de Axel Honneth. A teoria que indica uma necessidade de relações intersubjetivas entre as pessoas, visando que as relações sociais legitimem direitos uns dos outros pelo reconhecimento destes no diverso. Assim, o trabalho dialoga, por meio do método dedutivo, com os autores Michel Foucault e Judith Butler, bem como com juristas acerca da dignidade da pessoa humana e especialistas referente ao tema no esporte analisando determinações de comitês e federações oficiais.

Busca-se com esse método que a análise da inclusão social da pessoa transexual num ambiente tão dicotômico possibilite o reconhecimento social dela, e consequentemente, minimize o preconceito e erradique o estigma que marginaliza e remonta um caótico cenário dos direitos LGBT no Brasil. Justifica-se então, por meio deste raciocínio que a visão do esporte pode acarretar na promoção e garantia dos direitos humanos, bem como uma discussão efetiva no contexto social sobre gêneros e sexualidades. $\mathrm{O}$ artigo conta com a seguinte estrutura propondo um desenvolvimento científico: um breve panorama dos direitos das pessoas transexuais no Brasil, a fim de demonstrar a problematização histórica e corroborar o seu uso na aplicação das ações afirmativas; posteriormente, explica-se os principais embasamentos da teoria do reconhecimento de Axel Honneth e seus reflexos nos institutos jurídicos, como a dignidade e a liberdade; depois, garante um espaço para a discussão da dignidade da pessoa humana e o papel do Estado na sua efetivação; e, por fim, analisa-se o esporte como um instrumento social binário e os esforços para a inclusão das 
pessoas transexuais na sua prática, bem como uma breve análise do Caso Tiffany, de impacto recente no país.

\section{Breve panorama dos direitos das pessoas transexuais no Brasil}

As transexualidades são fenômenos da liberdade sexual, considerando a transição entre os gêneros a fim de condizer com a identidade do indivíduo. Nestes fenômenos, são consideradas as pessoas transexuais, travestis, cross-dressers, drags queen ou kings, e transformistas (dentro da transgeneralidade considera-se as primeiras categorias de identidade, e as outras de funcionalidade (JESUS, 2012, p. 7)), que transitam entre os gêneros. A identidade de gênero é um processo pessoal e característico da relação com a sexualidade. "É preciso entender esses temas da austeridade sexual não como uma tradução ou comentário de proibições profundas e essenciais, mas como elaboração e estilização de uma atividade no seu poder e na prática de sua liberdade" (FOUCAULT, 2014a, p. 30).

Vários ramos da pesquisa científica já se dedicaram ao estudo dessa identidade de gênero que transgrede padrões e normatizações consolidadas pela evolução da humanidade. Em primeiro momento, então, tal fenômeno fora encarado como uma patologia, com busca de tratamentos e curas. Atualmente, ainda com o preconceito enraizado sobre ela, entretanto, apresenta-se mais interpretações de cunho sociológico para a compreensão desta identidade. Para se compreender tal identidade, é preciso ampliar a interpretação e a maneira de fazê-la, o direito e seu método paradigmático, ainda não possui metodologia objetiva para o reconhecimento e tratamento. Assim, se faz necessário o diálogo interdisciplinar.

É necessário traçar desde o contato da medicina para posteriormente se encarar a repressão social. O termo "transexualismo", com o sufixo “- ismo" de semântica relacionada à patologias não é mais recomendado e é criticado pela militância trans, apesar da ainda presença no Cadastro Internacional de Doenças, na categoria F640. O Conselho Federal de Medicina, em consonância com as regras internacionais mantém o termo, na sua resolução $\mathrm{n}^{\circ}$ $1.955 / 2010^{3}$. Porém a temática no meio médico apresenta diversas pesquisas e atualizações no trato dos indivíduos que assim se identificam. É hoje um dos questionamentos da medicina

\footnotetext{
${ }^{3}$ Cf. CONSELHO FEDERAL DE MEDICINA. Resolução n ${ }^{\circ}$ 1.955/2010, de 03 de setembro de 2010. Disponível em http://www.portalmedico.org.br/resolucoes/cfm/2010/1955_2010.htm.
} 
moderna, desde o século passado, como compreender a condição da transexualidade ${ }^{4}$. No teor do documento normativo, é traçado alguns aspectos de como identificar o fenômeno, dentre eles, o desconforto com o sexo anatômico natural e o desejo expresso de eliminar os genitais, perder as características primarias e secundárias do próprio sexo e ganhar a do sexo oposto.

Em 2018, foi emitida uma resolução pelo Conselho Federal de Psicologia em que utiliza o termo "transexualidades", com o sufixo "- idade" indicando a ideia de estado e situação, além do plural indicando diversas formas de ocorrências do fenômeno da sexualidade $^{5}$. Desta maneira, tal resolução normativa promove a compreensão sem preconceitos e julgamentos a população que buscar os serviços desta classe de profissionais ${ }^{6}$. Assim, demonstra-se um esforço da humanização do tratamento ás pessoas com a identidade de gênero incompatível com suas genitálias, indicando até mesmo uma lacuna da própria dignidade humana. Se é uma questão de identidade, entende-se que este elemento perpassa a dignidade humana, e assim se demonstra como o primordial direito da população.

É necessário, portanto o conhecimento do panorama e da luta trans para compreender a pauta e os direitos reivindicados como essenciais para a própria manutenção da identidade. Precisa-se conhecer e reconhecer o outro para garantir a posição de titular de direitos, pois se não, tende-se à invisibilidade do sujeito. Nesse sentido, portanto, entende a Opinião Consultiva (OC) $\mathrm{n}^{\mathrm{o}} 24$, emitida pela Corte Interamericana de Direitos Humanos em novembro de 2017, que a identidade de gêneros e o respeito ao grupo deve ser promovido. Entre tantas, reflexõs sobre o tema, fala de segurança pública, saúde, gratuidade no serviço, e mudança do nome civil sem necessidade de cirurgia. A manifestação foi um grande marco na luta pelos direitos LGBT pois trouxe a postura da liberdade sexual e igualdade de gênero.

É dessa maneira que os tribunais e alguns instrumentos legislativos já vem se comportando no Brasil. O projeto de Lei 5002/2013 já previa o direito à identidade de gênero em âmbito legislativo, contudo, ela se encontra sem tramitação legislativa desde 2016. O referido instrumento normativo prevê, nos seus artigos inaugurais que: ““'toda pessoa tem direito ao reconhecimento de sua identidade de gênero [e que este] pode envolver a

\footnotetext{
${ }^{4}$ Cf. MATÃO, Maria Eliane Liégio et al. Representações sociais da transexualidade: perspectiva dos acadêmicos de Enfermagem e Medicina. Rev. Baiana Saúde Pública, 2010.

${ }^{5}$ Cf. BIANCON, Mateus Luiz. Educação em Sexualidades Crítica: formação continuada de professoras (es) com fundamentos na pedagogia histórico-crítica. 186 folhas. Tese (Doutorado em Educação para a Ciência e a Matemática) - Universidade Estadual de Maringá, 2016.

${ }^{6}$ Cf. CONSELHO FEDERAL DE PSICOLOGIA. Resolução $\mathrm{N}^{\circ}$ 1, de 29 de janeiro de 2018. Disponível em http://site.cfp.org.br/wp-content/uploads/2018/01/resolucao_cfp_01_2018.pdf. É importante notar que a resolução saiu no Dia Nacional da Visibilidade Trans no Brasil.
} 
modificação da aparência ou da função corporal através de meios farmacológicos, cirúrgicos ou de outra índole".

$\mathrm{Na}$ mesma linha de raciocínio, destacam-se os recentes instrumentos normativos, como a inclusão do campo de nome social no atendimento do SUS, assunto já consolidado e respaldado pela Portaria 1.820 de 13 de agosto de 2009 do Ministério da Saúde ${ }^{7}$, adicionada a Portaria 2.803 de 19 de novembro de $2013^{8}$, com as regras para a cirurgia de transgenitalização no sistema público de saúde. Ou ainda a Portaria $n^{\circ} 33$ de 17 de janeiro de 2018 do Ministério da Educação ${ }^{9}$, onde permite-se o uso do nome social de transexuais e travestis na Educação Básica. Sobre o nome ainda, a questão já teve resultado favorável no Superior Tribunal de Justiça, e seguiu entendimento na decisão histórica do Supremo Tribunal Federal, em março de 2018, retirando toda burocracia ou necessidade de laudos médicos ou processos judiciais para a alteração do nome e o sexo no registro, podendo realiza-la no próprio cartório. Ainda neste referido ano, o Ministério da Defesa indicou a obrigação de homens trans a realizar o alistamento militar, reconhecendo o seu gênero de identidade.

São decisões como estas que indicam a humanização e o crescimento do respeito à diversidade no Brasil. As críticas se aglomeram na necessidade do Poder Judiciário ter que resolver as situações de violação de direito ou distanciamento dos direitos humanos por parte da população trans, enquanto uma legislação federal poderia promover essas conquistas de maneira ampla ao país. A lacuna legislativa, pela cultura do país, ainda assombra a insegurança e demonstra uma incerteza dos direitos. A promoção dos direitos humanos existe e está demonstrando cada vez mais a preocupação com a inclusão social da população transexual, mas não é integralmente eficiente. E assim, cada vez mais o tema é abastecido de decisões pontuais e singulares, que garantem direitos e seguem o mesmo raciocínio humanista, mas é de árdua obtenção.

Seja por levantamento interno, realizado pela Associação Nacional de Travestis ou Transexuais com o monitoramento anual dos homicídios pelo país, indicando um a cada quarenta e oito horas ${ }^{10}$; ou internacional, realizado por diversos meios de comunicação sendo

\footnotetext{
${ }^{7}$ Disponível em http://bvsms.saude.gov.br/bvs/saudelegis/gm/2009/prt1820_13_08_2009.html.

${ }^{8}$ Disponível em http://bvsms.saude.gov.br/bvs/saudelegis/gm/2013/prt2803_19_11_2013.html.

${ }^{9}$ Disponível em https://abmes.org.br/arquivos/legislacoes/Port-MEC-33-2018-01-17.pdf.

${ }^{10}$ Cf. ANTRA. Mapa dos assassinatos de Travestis e Transexuais no Brasil em 2017. Brasil, 2018. Disponível em: https://antrabrasil.files.wordpress.com/2018/01/relatc3b3rio-mapa-dos-assassinatos-2017-antra6.pdf.
} 
um deles a importante organização europeia a TransRespect ${ }^{11}$, os números são alarmantes. A vida da pessoa transexual é alvo além do preconceito, mas também do homicídio e de violação dos direitos humanos. E, para o cenário interno, as conclusões são uníssonas: o Brasil é o país que mais mata pessoas transexuais. E todo e qualquer direito conquistado demonstra mais um passo visando o fim do preconceito e a mudança deste caótico cenário de mortes.

\section{A teoria do reconhecimento social e da liberdade moral de Axel Honneth}

É básico à teoria honnethiana, que aqui indica o caminho que baseia o estudo, que o reconhecimento social se define além de uma figura apendicular de condicionamento externo, mas também uma dependência recíproca de existência intersubjetiva (HONNETH, 2015, p. 94). "Honneth adota uma compreensão muito ampla de reconhecimento e enquadra na categoria demandas e reinvindicações que vão muito além das políticas de identidade, vocalizadas pelos movimentos sociais contemporâneos" (SARMENTO, 2016, p. 248). Em uma sociedade pautada por questões culturais, sociais e políticas, a identidade que permeia e expressa essa liberdade é das mais diversas possíveis. Assim sendo, a identidade mostra ao mundo externo, o que a liberdade compreende do interno e que busca reciprocidade.

Honneth defende, aos passos de Aristóteles e Hegel, que essa subjetividade do homem (tanto identitária, como preconceituosa e de reconhecimento) tem íntima relação à coletividade da pólis $(2009$, p. 43). No mesmo sentido, Lipovetsky defende que "até os comportamentos internos são pegos na engrenagem do externo, do que são prova: o frenesi consumista, o doping, os esportes radicais, os assassinos em série, as bulimias, a anorexia, a obesidade, as compulsões e os vícios" (2004, p. 55).

O reconhecido é reconhecido como válido imediatamente, por ser seu ser, mas precisamente esse ser é gerado a partir do conceito; é se reconhecido. O homem é necessariamente reconhecente. Essa necessidade é a sua própria, não o nosso pensamento em oposição ao conteúdo. Como reconhecer, ele próprio é o movimento, e esse movimento supera justamente seu estado de natureza: ele é reconhecer (HONNETH, 2009, p. 85-6)

Assim, o homem, segundo o filósofo alemão, toma para si sua identidade, e a reconhece como tal, quando ele é reconhecido. E é reconhecido, porque assim também faz,

\footnotetext{
${ }^{11}$ In. "30th March 2017: Trans Day of Visibility Press Release". Disponível em: http://transrespect.org/wpcontent/uploads/2017/03/TvT_TMM_TDoV2017_PR_EN.pdf
} 
em via dupla, um processo de reconhecimento do outro. É um "ingresso da vontade individual na realidade social" (HONNETH, 2009, p. 95). Reconhece de tal maneira, que a criatura humana é importante para a coletividade que ali está presente, e se conscientiza aqui da sua própria subjetividade (HONNETH, 2009, p. 128), o coletivo auxilia a própria interpretação social da sociedade, sem indicar um pleonasmo linguístico.

Essa subjetividade e consciência sobre o papel do homem na sociedade assistencial, mas também dependente - prova que a liberdade ao se firmar na trajetória social, dessa maneira, também ajuda na construção de uma base ao ordenamento jurídico. "A dependência caracteristicamente humana de reconhecimento intersubjetivo está configurada sempre pelo modo particular de institucionalização das mútuas relações de reconhecimento na sociedade" (BRAGA; SCHUMACHER, 2014, p. 377).

É nessa manutenção da harmonia social que o Estado Democrático de Direito deve interferir para garantir uma noção de reconhecimento recíproco, a fim de estabelecer a promoção da dignidade humana (inerente à liberdade, igualdade e identidade), ainda como um princípio básico de sua forma social de governo - até mesmo constitucionalmente postulado. Contudo, não é uma escolha automática, ser ou não livre, igual ou quem se é, algumas instituições, seja baseado em interesses institucionais acabam por comandar as escolhas mais íntimas do ser humano (SOUZA, 2015, p. 41).

Como se compreende na Teoria do Estado ou na Ciência Política, a lei deriva da sociedade e tem sua finalidade nela. É mister reconhecer a coletividade na letra e interpretação do instrumento legislativo, assim promovendo a igualdade e liberdade da população, retomando o princípio da dignidade da pessoa humana. Assim, quando se retoma a consciência do Estado, como o instituto que promove a ideia da manutenção da harmonia social e justa e de todas as tutelas jurídicas possíveis para a defesa do direito da identidade da pessoa transexual. Até porque o ordenamento jurídico brasileiro se norteia pelo ideal da dignidade da pessoa humana, que irá ainda ser destacada neste estudo.

“O princípio da dignidade humana visa a proporcionar uma proteção integral à pessoa, e não tutelar aspectos previamente recortados de sua personalidade e dos seus direitos" (SARMENTO, 2016, p. 89). Não é a dignidade humana uma carta coringa a todos os tipos de problemas no viés jurídico, tampouco a liberdade ou a igualdade. A defesa do trabalho não encara o chavão jurídico como caminho mais fácil, mas sim pela teoria do 
reconhecimento social de Axel Honneth e o respeito às sexualidades, aqui trazida pelo entendimento de Michel Foucault (2014).

Não se poderia deixar de citar em um artigo com o foco nas transexualidades, uma necessária e recorrente citação à Judith Butler e a sua perspectiva sobre gêneros (BUTLER, 2016). Não é o intuito deste trabalho uma análise sobre as teorias de gênero ou as demonstrações da sociedade, mas o reconhecimento dos direitos transexuais e uma análise mais prática quanto ao esporte (que será vista no próximo item). Assim, perante uma ou outra raiz social de preconceito ou estigma com origem nas dicotomias, é abordada por Butler, no livro Problemas de Gênero: Feminismo e a Subversão da Identidade, a questão de como essas diferenças compõem a diversidade.

\begin{abstract}
O que encontrei de novo no livro Gender Trouble: feminism and the subversion of identity, foi a possibilidade de entender as fissuras que se abrem pelas agências de pessoas que tentam reproduzir as normas, mas o resultado esperado não é o reconhecimento. Portanto, as noções de paródia e de performance foram centrais. Uma mulher trans pergunta: "por que as pessoas me tratam mal? O que tem de errado no meu jeito?". Ela foi socializada como menino. Seu jeito de andar e de se vestir são os socialmente reconhecidos como de menino. Estas marcas, que eu chamo de "herança de gênero", ficam no corpo. As pessoas que a olhavam se perguntam: "Homem ou mulher?". É necessário o olhar do outro para conferir a minha existência. Concordo com a apropriação que Butler faz da teoria do reconhecimento de Hegel: ninguém faz seu gênero isoladamente, secretamente. [...] Você precisa do olhar do outro para se produzir no gênero. Isto é válido para todos nós. Daí a força regulatória do gênero. Neste sentido, a teoria da performance me pareceu interessante, pois me dava um suspiro, um oxigênio para conseguir entender que os processos de produção e reprodução têm fissuras e são nestes pequenos espaços que habitam a possibilidade de mudança da sociedade. (BENTO, 2017, p.129)
\end{abstract}

Assim o que se compreende e conclui tal diálogo teórico é que o reconhecimento social é uma abertura à mudança da sociedade. É o objeto da teoria de Honneth, o reconhecimento social, que além de um processo legitimador de liberdades e individualização, se propõe a comprometer a coletividade em harmonia com a diversidade e com as diferenças reconhecidas. Longo caminho a percorrer ainda resta, contudo, por tal teoria, é notável a necessidade de atuação efetiva do Estado de compreensão das diferenças e dos anseios e necessidades mais peculiares de cada ser singular diante de sérios estigmas e preconceitos jurídicos e sociais, para conduzir ao fim problemas como o preconceito e a marginalidade.

É claro, que "a livre expressão do amor e do afeto só se tornou possível porque está sustentada em um novo discurso sobre a sexualidade" (PEREIRA, 2001, p. 29), e aqui podese compreender também a expressão de gênero como um elemento deste novo discurso. 
Quando se percebe essa simbiose e troca de informações do comportamento humano com o seu ambiente físico-orgânico ${ }^{12}$, é importante demonstrar o como o discurso acadêmico e, mais importante legislativo, judiciário e político está em consonância com seus sujeitos. Assim, amparado nestas duas teorias sobre a realidade e suas trocas com o meio espacial, orgânico e social, o autor alemão propõe, e aqui se defende, que:

Uma forma tradicional de reconhecimento jurídico dessa espécie já concede ao sujeito uma proteção social para sua dignidade humana; mas esta está ainda inteiramente fundida com o papel social que lhe compete no quadro de uma distribuição de direitos e encargos amplamente desigual (HONNETH, 2009, p. 181).

Deste trecho, vislumbra-se a importância do reconhecimento para a identidade, e por tanto da mudança social. Essa análise possui muitas características relacionadas à lógica kantiana, já que o homem não pode ser um instrumento de outras pessoas para alguma vontade, mas de suas próprias noções e compreensão de si mesmo ${ }^{13}$ (SARLET, 2007, p. 382). Destarte, o reconhecimento social é uma teoria com estrita relação à liberdade moral, também nas reflexões do filósofo alemão (HONNETH, 2015), que não remete à ideia de que se usa o outro como um instrumento, mas sim, a ideia de ser reconhecido remete à formação de uma dignidade humana dentro de uma coletividade e socialidade (HONNETH, 2009). Essa troca dependente entre os pares de legitimação da liberdade demonstra uma integração da liberdade sexual dentro da dignidade, pautada pelo respeito à igualdade e a identidade.

A liberdade moral não faz simplesmente a pessoa escolher atitudes com seu próprio ponto de vista, mas acredita numa atitude mais universal, levando em conta uma ação com reflexos mais coletivos e social, não sucumbindo, contudo, a sua própria dignidade (HONNETH, 2015, p. 180-1). De certa forma, as relações individualizadas guardam reflexos e consequências sociais pelo meio em que estão envolvidas. Quando a lógica do reconhecimento social demonstra a preocupação com as diferenças e as legitimações que são conferidas subjetivamente.

"A liberdade moral deve significar que o sujeito possui uma margem de ação geralmente aceita e informalmente concedida, para que tais normas morais sejam garantidas" (HONNETH, 2015, p. 192-3). Desta forma, consegue-se encaixar várias formas de

${ }^{12}$ Honneth esclarece que nesta sua premissa muito se compreende do Modelo de Talcott-Parsons. Portanto, cf. PARSONS, Talcott. The social system. Psychology Press, 1991.

${ }^{13}$ Cf. KANT, Immanuel. Fundamentos da metafísica dos costumes. Ediouro, 1993. 
reconhecimento como uma maneira de perceber a moral assentida. Seja pelo respeito de forma passiva, a tolerância com o aceite ou a hospitalidade com a atividade cíclica, demonstram-se efeitos e consequências ao comportamento de liberdade que se fundamentará em escolhas morais. Não se promove o fim da identidade com essas atitudes, cada um garante a sua pessoalidade e continua com sus próprios interesses, contudo, não se esquece o significado social dos reflexos dessas relações surgidas (HONNETH, 2015, p. 203). Tal aspecto ilustrado no exemplo do artigo, permite que uma pessoa trans seja inserida no cenário desportivo não suprimindo a identidade da equipe, mas promovendo a dignidade daquela dentro da categoria que se identifica. Além de consolidar o direito ao esporte, constitucionalmente garantida e a promoção dos direitos humanos.

\section{A questão da dignidade da pessoa humana e o papel do Estado na inclusão social}

Compreende-se do estudo da liberdade sexual pautado na História da sexualidade de Michel Foucault (2015; 2014a; 2014b), que a base principal para a compreensão daquela pode se inferir como uma faceta da dignidade humana. "A dignidade é essencial, em primeiro lugar para o reconhecimento da fundamentalidade de direitos que não estejam inseridos no catálogo constitucional de direitos e garantias fundamentais" (SARMENTO, 2016, p. 84). Tão importante quanto é reconhecer o caráter multifacetado do conceito (BARROSO, 2013, p.63) e não restringir a sua qualificação apenas ao campo jurídico. O grande desafio do Estado, nas questões de gênero e sexualidades, é, inquestionavelmente, entender tal fenômeno tão distante do viés paradigmático da ciência jurídica. Assim, reconhecendo que a dignidade humana carece desse viés interdisciplinar, é necessário reconhecer as particularidades de cada indivíduo, para a garantia de uma justa ordem social - seja entendido como integrante da categoria de direito humano ou fundamental (CASTRO, 2016, p. 86).

A construção da dignidade da pessoa humana no ordenamento jurídico brasileiro se mostra necessária quando se encara o conjunto de leis como um instrumento de efetivação e prática. Não haveria como ser diferente, portanto, e um norte à pessoa humana é preciso ser dado para o ordenamento, para que se possa proteger e promover as relações sociais e da coletividade. Diante disso, as próprias formações legais - tanto positiva como negativa agem diante dessa conjectura e demonstram a multiplicidade de aparições possíveis da dignidade como uma forma de fundamentar as regras (SARLET, 2012, p. 70). 
Assim, é justo dizer que essa noção sobre dignidade da pessoa humana não é lugarcomum sobre as questões acerca dos direitos do homem, e nem poderia $\operatorname{ser}^{14}$. A devirdignidade baseada em vários outros aspectos e até mesmo numa responsabilidade muito maior, com viés multidisciplinar de conceitos e reflexos da sua carga valorativa, demonstram que as noções social, coletiva, psicológica, intrínseca e interna - atual e por toda a história da sexualidade, compreendem a sua identificação dentro do instituto. É a ideia, portanto, da busca da "superação de qualquer visão unilateral e reducionista e a promoção e proteção da dignidade de todas as pessoas em todos os lugares" (SARLET, 2007, p. 385). É necessário compreender as transexualidades como um fenômeno complexo e de ampla abrangência no comportamento humano, para não vislumbrar a dignidade da pessoa humana como um caminho fácil de construir sua natureza jurídica.

A moral sexual precisa ser um conhecimento de si mesmo, para que o indivíduo possa construir e fazer valer de sua soberania $^{15}$, assim o desenvolvimento deste autoconhecimento não demonstra um cerceamento do próprio anseio, mas sim a determinação da sua subjetividade moral (FOUCAULT, 2014b, p. 86-7). Conhecer sobre o seu próprio sexo - e todas as suas vertentes de exteriorização social - indica um autoconhecimento que se completa a integridade pelo reconhecimento do outro e da coletividade que cerca o indivíduo. Como já declarado, o sexo não se condiz a uma padronização, nem mantém uma expectativa única como fenômeno, assim, é contraditório dizer que esta ou aquela forma de liberdade sexual garantiriam a dignidade humana. Por isso, insistimos no uso da palavra sexualidades na forma ortográfica do plural, justamente a fim de indicar as suas várias possibilidades ${ }^{16}$.

Judith Butler, uma das pioneiras nessa nova formulação de encarar a sexualidade como um fenômeno científico, defende que a identidade de um indivíduo deve estar para além

\footnotetext{
14 “ [...] o conceito de dignidade da pessoa humana obriga a uma densificação valorativa que tenha em conta o seu amplo sentido normativo-constitucional e não uma qualquer ideia apriorística do homem, não podendo reduzirse o sentido da dignidade humana à defesa dos direitos pessoais tradicionais, esquecendo-a nos casos de direitos sociais, ou invocá-la para construir 'teoria do núcleo da personalidade' individual, ignorando-a quando se trate de direitos econômicos, sociais e culturais" . Daí decorre que a ordem econômica há de ter por fim assegurar a todos existência digna (art. 170), a ordem social visará a realização da justiça social (art. 193), a educação o desenvolvimento da pessoa e seu preparo para o exercício da cidadania (art. 205) etc., não como meros enunciados formais, mas como indicadores do conteúdo normativo eficaz da dignidade da pessoa humana" (SILVA, 1998, p. 92).

${ }^{15}$ Cf. FISCHER, Rosa Maria Bueno. Foucault e, O Desejável Conhecimento do Sujeito. Educação \& Realidade, v. 24, n. 1, 1999.

${ }^{16}$ Cf. BIANCON, Mateus Luiz. Educação em Sexualidades Crítica: formação continuada de professoras (es) com fundamentos na pedagogia histórico-crítica. 186 folhas. Tese (Doutorado em Educação para a Ciência e a Matemática) - Universidade Estadual de Maringá, 2016.
} 
de uma normatividade ou determinações compulsórias, assim é entendido que todas as formas, expressões, incoerentes ou não com padrões, que alguém poderá vir a ter, serão reconhecidas (BUTLER, 2016, p. 43). Por isso, não se padroniza o complexo estudo de gêneros e sexualidade, e assim, se reflete na asseguração da dignidade da pessoa humana, afinal "o principal déficit de efetividade da dignidade da pessoa humana no Brasil deriva [...] de uma cultura muito enraizada que não concebe todas as pessoas como igualmente dignas" (SARMENTO, 2016, p. 67).

A dignidade da pessoa humana se baseia em fases constitutivas que encaram o valor intrínseco da pessoa, a autonomia dela, além de se relacionar com o mínimo existencial para sua vida e o reconhecimento disso perante seus pares. Tais componentes não são isolados uns dos outros. Eles se conflitam e as suas demarcações não são nítidas, mas comunicativas e simbióticas (SARMENTO, 2016, p. 93). Assim, aquilo que depende de um reconhecimento social pode demonstrar, sem perda de conteúdo ou carga jurídica, uma noção do valor próprio da pessoa, recorrente a sua identidade. Pois bem, quando se fala nas questões de sexualidade ou transexualidades, o entendimento das múltiplas liberdades e/ou identidades fica cada vez mais intrincada ao direito e seu amparo paradigmático de atuação.

\footnotetext{
A aproximação com a transexualidade é reveladora das convenções sociais sobre masculinidade e a feminilidade. Diariamente profissionais da saúde, juízes, advogados, professores, parlamentares, amigos, familiares são instados a se posicionar e encontrar sentidos para as demandas de pessoas que reivindicam o pertencimento a um gênero distinto daquele que lhe foi imposto (BENTO, 2008, p. 13).
}

É defensável, portanto que o direito não regule todas as interações humanas, a fim de garantir a sua harmonia por reações pré-moldadas, contudo, a promoção dos direitos humanos, longe do preconceito e da violência deve ser o norte do ordenamento. "O Direito pode se tornar perigosamente autoritário se pretender regular todas as interações humanas com o fito de promover o reconhecimento intersubjetivo, asfixiando e roubando a espontaneidade das relações sociais” (SARMENTO, 2016, p. 259). Por conseguinte, este entendimento de afirmar que a dignidade da pessoa humana se infere neste ponto é dar uma noção principiológica ao caminho tomado, e não persuadir o ordenamento jurídico a conduzir todos os tipos de interação sexual relacionada à liberdade e revolução sexuais.

Não contraditório a isso, o ordenamento jurídico possui na instrumentalização de ações afirmativas uma ferramenta de corrigir algumas desigualdades na sociedade. Elas 
podem possuir caráter temporário ou especial, a fim de garantir os pressupostos que se desenhou neste artigo. As ações afirmativas têm a sua base teórica muito relacionada ás condições de igualdade, enquanto a teoria do reconhecimento social na liberdade, contudo aqui diante do recorte metodológico adotado, as duas se confluirão no tocante à dignidade da pessoa humana. No caso específico, na busca da pessoa transexual ser livre com sua identidade e buscar a correção da desigualdade, assegurando-lhe a sua dignidade.

[...] ação afirmativa passou a significar a exigência de favorecimento de algumas minorias socialmente inferiorizadas, vale dizer, juridicamente desigualadas, por preconceitos arraigados culturalmente e que precisavam ser superados para que se atingisse a eficácia da igualdade preconizada e assegurada constitucionalmente na principiologia dos direitos fundamentais (SILVA, 2003, p.63).

Deve-se ressaltar que tais medidas não buscam ou congratulam o reconhecimento integral dos direitos da classe vulnerável assim de maneira especial ou temporária. Elas são maneiras de adequar tal classe ao contexto que a sociedade se encontra (ROTHENBURG, 2008, p. 83), marginalizada ou estigmatizada entre os principais aspectos jurídicos e sociais que está a sociedade. $\mathrm{O}$ mecanismo se pauta na questão de garantir ideais de igualdade para todas as pessoas conforme a legislação prevê. Entre ideias de igualdade formal ou material, se busca uma igualdade real, nas condições fáticas e concretas pelo mandamento da igualdade (SILVA, 2003, p. 75).

A interpretação do princípio da dignidade humana juntamente com a teoria do reconhecimento social, demonstra que as ações afirmativas possuem o escopo de minimizar as diferenças e promover essa inclusão social. A necessidade do legislador é compreender que as mais diversas formas de identidade da população, e reconhecer que todas, sem distinção, também devem se beneficiar com as inovações que a lei traz. Mesmo que ela não represente uma voz ativa no cenário político, a marginalização gera preconceito e graves problemas no funcionamento da engrenagem social como um todo, desarmonizando a coletividade e prejudicando os direitos humanos de compreensão global.

O que se depreende desta conclusão é que para a inclusão social das pessoas transexuais se depreende a necessidade de regular ou manifestar a interferência do Estado na regulação dele. É necessário, dentro da luta pelos direitos acima elencados no ordenamento jurídico, e diante de todo o estigma nacional, sendo o país com o maior número de mortes da 
população trans no mundo, a inclusão social é necessária. E ações afirmativas se demonstram como uma das possibilidades de resolver esse debate. Aqui, neste artigo, pela brevidade do estudo apresentado, se indica uma possibilidade que é, atualmente em voga, a inserção de atletas trans no esporte, com definições de respeito e longe de polêmicas indevidas. A conduta do Estado em garantir essa situação demonstra que a sua responsabilidade possui impacto individual e coletivo.

Por isso, resta claro, que a partir do princípio jurídicos aqui apresentados, a incapacidade de se prescindir de população LGBT a titularidade de direitos humanos, uma vez que a própria Declaração, traz em seu artigo primo a não discriminação por qualquer característica que diferencie ou determine tratamento diferente entre as pessoas. Digno ao homem é a oportunidade que ele tem de fazer valer seus direitos. E permitir, assim, que ele tenha o livre arbítrio dentro do limite de seus deveres e obrigações. Podendo ser livre com suas convicções tanto culturais, sociais, políticas e sexuais. E assim reconhecido dentro de seu país, com a identidade que evidencie a sua própria titularidade de direitos.

\section{A inclusão social dos atletas transexuais no esporte: a acepção coletiva}

O esporte é um instrumento social que está presente no consciente coletivo. Seja pela emoção que traz a torcida ou a promoção direta da saúde, bem-estar e lazer, que são direitos constitucionais, ele tem uma alta visibilidade no cenário brasileiro. Na Constituição Federal, o artigo 217 traz a sua regulamentação de dever do Estado. Segue: “Art. 217. É dever do Estado fomentar práticas desportivas formais e não-formais, como direito de cada um, observados: I a autonomia das entidades desportivas dirigentes e associações, quanto a sua organização e funcionamento; [...]". Nesta compreensão é dever do Estado, dentro dos tantos constitucionais garantir a prática desportiva, e por meio dessa administração indireta recorrer às entidades dirigentes e associações, uma forma de regularização e manutenção do esporte na sociedade.

Pela Carta Internacional da Educação Física e do Esporte da UNESCO, lançada em 1978, e atualizada em 2016, o esporte é considerado um dos direitos humanos, e, portanto, de ampla abrangência e de absoluta titularidade, sem resguardar qualquer preconceito. Ainda, se encara o esporte como um elemento dotado de valores éticos e de integridade à sociedade, além disso, deve ser praticado a fim de garantir a sustentabilidade social do seu meio. Ou seja, entende-se nesta interpretação que o esporte deve ser amplamente disponível a todas as pessoas, e o não reconhecimento de alguns comprometeria seus valores e caráteres éticos 
traçados pelo documento da Organização das Nações Unidas para a Educação, a Ciência e a Cultura (UNESCO).

Por estar presente na realidade da sociedade brasileira, o esporte livre e abrangente a todas as pessoas possui a sua acepção coletiva, além de ser uma forma de efetivação dos direitos da Constituição Federal, inclusive com grandes referências ao gênero e sexualidades ${ }^{17}$. Isso se explica com a noção que se tem socialmente que o esporte é um espaço masculino e viril predominante ou exclusivo. E assim, as questões feministas, transgêneras e LGBT, como fogem à tal padronização sempre encontra mais dificuldades para a inserção deste grupo neste meio.

\begin{abstract}
Ao eliminarem do horizonte analítico o determinismo biológico e os binarismos, estes estudos favorecem a aceitação da profusão de feminilidades e de masculinidades, da permeabilidade entre as fronteiras corporais e a não fixidez das identidades. Permitem, ainda, compreender que o esporte não é um campo "naturalmente" masculino, nem mesmo aquelas modalidades que exigem maior força física e vigor: como qualquer outra instância social, o esporte é um espaço de generificação, não porque reflete as desigualdades e diferenciações da sociedade em geral, mas, fundamentalmente, porque as produz e reproduz (GOELLNER, 2007, p. 190).
\end{abstract}

A acepção coletiva se encontra baseada pela teoria do reconhecimento social e também pelo escopo das ações afirmativas. Assim, explica-se: a pessoa reconhecida no âmbito desportivo entra no ciclo de reconhecimento e tem a sua liberdade defendida e escancarada na sociedade, desta maneira, ao reconhecer a pessoa transexual, no caso deste estudo, apta a participar, reconhece àquela a sua definição e conformidade de identidade perante seus pares. Além do escopo das ações afirmativas, que pelo seu caráter especial, tendem a promover tais inclusões devido aos estigmas e preconceitos culturais arraigados na sociedade.

$\mathrm{Na}$ realização de uma ação afirmativa como essa de inclusão social no esporte, é necessário, portanto, atentar-se a um ambiente apto e propício para que a ação afirmativa especial ocorra de maneira eficaz e eficiente. As teorias precisam de um ambiente propício para que sua prática caminhe a valorar bons resultados, e o papel do Estado, mais uma vez

\footnotetext{
17 "Viewed historically, sports culture doesn't simply reflect the prevailing gender and sexual biases of its time; it helps to shape them. The brutal machismo pounded into male athletes from the earliest age - they are told not to "throw like a girl" or to "man up" and play through extreme pain - reinforces the denigration of femininity and vulnerability, as does the classic coaching tendency to mock players by calling them "ladies" or "girls" when they're slow or when they drop the ball" (WOLF, 2011, p. 29-30).
} 
aqui destacado, é proporcioná-los. Assim, pode-se destacar algumas ações, como a criação de um ambiente livre, o incentivo da prática do esporte entre todas as pessoas e que estas possam realiza-las conjuntamente para não escancarar as diferenças, bem como recusar modelos programados pelo senso comum de distinção do esporte (GOELLNER et. al., 2009, p 18)

Buscar a inclusão social no esporte é uma forma de garantir uma visibilidade e representatividade da situação e colaborar para que o preconceito ou estigma se cesse. Ainda, por meio dessa ação afirmativa é fácil apontar que também identificar "uma mudança cultural a partir da disseminação de conceitos, comportamentos e atitudes igualitárias, que valorizem a diversidades e as diferenças culturais entre os sujeitos [... e] desestabilizar os discursos discriminatórios (racistas e sexistas)" (GOELLNER et. al., 2009, p. 6-7). No caso específico das pessoas transexuais, tais ações são de reconhecimento próprio da identidade que elas se reconhecem. É a ideia básica da teoria de Axel Honneth que se concretiza ao dar espaço para a liberdade de cada um.

"O princípio da inclusão consiste na incorporação de corpos que se encontram fora dos padrões de normalidade (física, fisiológica, comportamental, social) estipulados por determinado grupo social, e que necessitam de superação e compreensão daqueles inseridos nos padrões de normalidade para serem aceitos" (MARQUES et. al. 2009, p.369).

Os documentos mais importantes de promoção da igualdade e liberdade do país, para ilustrar alguns: Programa Brasil sem Homofobia (2004) Plano Nacional de Políticas para as Mulheres (2006); Plano Nacional de Educação em Direitos Humanos (2007); e Programa Nacional de Direitos Humanos (2010), visando a promoção e divulgação dos Direitos Humanos entre a coletividade, demonstram todos a necessidade de ações afirmativas de inclusão social da população LGBT. Pois, quando se compreende as finalidades sociais na sociedade, a ideia da sexualidade e do gênero apresentam resistências (CARVALHO, 2014, p. 247) Os lançamentos desses propõem iniciativas a findar o preconceito e inserir a pessoa com a dignidade, que lhe é constitucionalmente garantida. E neles, apresenta o esporte como um meio formador da cidadania. Assim, incentivar tal inclusão social no Esporte pelo Estado é uma forma de se garantir os direitos humanos estabelecidos.

Claro que dentro da pasta social de um país, existem direitos mais urgentes a uma atuação do Estado, mas o presente artigo se demonstra necessário devido aos casos práticos que apareceram no país ultimamente e geraram controvérsias. Assim, o Estado precisa, na 
busca da promoção dos direitos a todas as pessoas e também de garantir a harmonia coletiva estar atento a essas situações e garantir que a melhor decisão seja tomada. E, como visto e debatido aqui, a ideia da dignidade da pessoa humana e da busca pelo reconhecimento social é multifacetado, e precisa do diálogo entre institutos para se compreender melhor a questão.

Assim, do mesmo jeito que se busca a sociologia, antropologia para a fonte do direito material, é necessário buscar o diálogo com outros meios para garantir a questão da trans, com os conceitos de medicina e psicologia integrados à melhoria e promoção dos direitos humanos. O viés padronizado do direito, por vezes, dificulta a visão e entendimento de fenômenos, como os das sexualidades, e consequentemente auxilia no processo de perpetuação do preconceito social. Assim o reconhecimento, dentro da teoria do filósofo alemão, indica uma base teórica efetiva a compor uma mudança por meio das ações afirmativas e promover esta inclusão social.

É sabido e aqui se traz o caso prático para ilustrar a análise feita pelo artigo do Caso Tiffany. Tiffany Abreu é uma atleta transexual que integra o time feminino de vôlei de quadra do time Vôlei Bauru ${ }^{18}$. A questão não é nem sobre o seu desempenho no time na Super Liga de Vôlei, a atuação de uma atleta trans sendo respeitada a sua identidade e permitindo que a sociedade a reconheça da forma que ela se vê é o mais importante fato a ser protegido ${ }^{19}$. Entretanto, a boataria polêmica sobre o caso, dada pela mídia a cada posição de atletas do meio desportivo, ou perante a omissão dos órgãos técnicos é pontual à manutenção dos preconceitos. A questão demanda um diálogo interdisciplinar aberto de encontrar padrões objetivos (de cunho fisiológico ou hormonal, como, por exemplo, o teste de gender verification da Federação Internacional de Futebol $^{20}$ ), e evitar a ideia de "privilégios" ou

\footnotetext{
${ }^{18}$ A notícia vem sido amplamente divulgada na imprensa, e conta com notificações à imprensa de caráter oficial sobre o posicionamento dos órgãos oficiais referentes ao Comitê Olímpico Internacional, a Federal Internacional de Vôlei e a organização do Vôlei Brasileiro. Disponível em: https://globoesporte.globo.com/volei/noticia/levavantagem-consultora-do-coi-nao-acredita-em-reviravolta-do-caso-tifanny.ghtml. Acesso em 18 de fevereiro de 2018. E também, https://globoesporte.globo.com/volei/noticia/apos-reuniao-medica-fivb-ratifica-a-inclusao-detransgeneros-no-volei.ghtml. Acesso em 18 de fevereiro de 2018.

${ }^{19}$ Afinal, numa interpretação da teoria da performatividade de Judith Butler (2016), é possível compreender que "O corpo é muito mais do que uma construção biológica e social; é produto da cultura, das tecnologias, dentro de uma dimensão linguística. O corpo não está definido a priori e é um território amplo a ser explorado, que a partir de suas performatividades nos posiciona nos limites das normatividades corporais e de gênero instituídas" (CAMARGO; KESSLER, 2017, p. 194). Assim, não se pode compreender tão simplesmente essa questão, tendo em vista que a identidade transgênera é mais complexa que a dicotomia masculino/feminio, conforme já exposto aqui, nas ideias de Berenice Bento (2008, p. 13).

20 "A testagem foi implementada pela FIFA no mesmo ano da Copa do Mundo de Futebol Feminino 2011 (na Alemanha), sob o argumento de que hormônios androgênicos promovem melhorias no desempenho, em relação à força, potência e velocidade, servindo como uma vantagem competitiva. Conforme a entidade esportiva, os
} 
"vantagens", se cientificamente eles existirem. A pessoa transexual não tem controle sobre o corpo dela se desenvolver em desacordo com o gênero que ela se identifica fazer parte, e se compreender a questão à luz da subjetividade do esporte, este é o pior privilégio que ela pode ter, aquele que a remete a uma identidade em que não se reconhece.

Os procedimentos adotados para as atletas transexuais tinham altas críticas pois se resultavam em padronizações, ou erros diante da consideração psicológica ou visual dos atletas. Como se vê, a discussão é muito baseada na tal "vantagem", já que não se tem histórico de atletas homens transexuais que geraram polêmicas ou foram submetidos a testes. Assim, o que hoje se reconhece mundialmente são níveis de testosterona abaixo de 10 nanomols por litro de sangue, se afastando de padrões relacionados ao genótipos e fenótipos, ou necessidade de cirurgia, mas, ainda, tal decisão mantém a necessidade de um acompanhamento médico (CAMARGO; KESSLER, 2017, p. 218). Neste sentido, a posição do COI indica que "as mudanças cirúrgicas de mudança de sexo (cirurgia de transgenitalização) não são necessárias para garantir uma competição justa e podem ser inconsistentes com o desenvolvimento de leis e dos direitos humanos" (COI, 2015, p. 2) ${ }^{21}$. Tal decisão teve amplo reflexo nas Olímpiadas do Rio de Janeiro em 2016, e foi acatada pelas federações internas brasileiras.

O papel do Estado, dentro de suas esferas da administração direta (promoção dos direitos fundamentais e humanos) e indireta (a manutenção de entidades autônomas da regulação dos direitos desportivos), deve buscar sempre esse respeito aos atletas (individuais e as equipes), bem como buscar posicionamentos com profundidade científica e amplamente harmoniosa com a coletividade. A teoria do reconhecimento social propõe que a liberdade, e todos os outros direitos e institutos jurídicos que por ela perpassam, precisam dessa diversidade e das diferenças, para que tenha os reconhecimentos. Assim, a acepção coletiva dessa medida por parte do Estado é garantir o respeito micro e macro da dignidade da pessoa humana, erradicando preconceitos e estigmas e compreendendo que a identidade é a mais peculiar característica do ser humano que compõe a sociedade como ela é.

procedimentos de verifi cação podem ser aplicados em ambos os "gêneros" em caso de dúvida substancial. Entretanto, não existe nenhum registro de que homens tenham sido verifi cados. Em 2013, a jogadora sulcoreana Park Eun-Seon foi submetida ao teste" (CAMARGO; KESSLER, 2017, p. 200).

${ }^{21}$ Cf. IOC Consensus Meeting on Sex Reassignment and Hyperandrogenism November 2015. Disponível em https://stillmed.olympic.org/Documents/Commissions_PDFfiles/Medical_commission/2015-

11_ioc_consensus_meeting_on_sex_reassignment_and_hyperandrogenism-en.pdf. Acesso em 26 de fevereiro de 2018. 


\section{CONCLUSÃO}

O escopo do trabalho foi reconhecer a acepção coletiva da inclusão social de atletas transexuais no esporte, bem como o papel do Estado neste cenário, ambas situações à luz da teoria do reconhecimento social de Axel Honneth, e diálogo com outros importantes nomes da área do esporte, direito e gêneros e sexualidades. O que se apresenta, em conclusão, é que ao se reconhecer a dignidade da pessoa humana como um instituto jurídico que perpassa pelos ideais de identidade, liberdade e igualdade, a teoria utilizada como referencial teórico comprova que a inclusão social trazida no artigo é, de fato, efetiva para a promoção de direitos humanos e asseguração da harmonia coletiva.

Em suma, a teoria do reconhecimento social precisa das relações recíprocas de conhecimento das pessoas para legitimarem direitos. Desta forma, quando se insere pessoas transexuais, com passado e contexto social caótico e marginalizado comprovado por números e estatísticas, no esporte, que tem uma raiz binária de atuação, demonstra-se uma abertura ao novo e aos fenômenos relacionados ao tema, como uma forma de adaptação do cotidiano e das relações sociais. Assim é importante que esses testes e resoluções oficiais pelos comitês e federações do esporte, vinculada à administração do Estado promova a conscientização e a constante atualização de seus preceitos médicos, hormonais e fisiológicos. Pois, essa preocupação demonstra a amplitude e abrangência da titularidade do esporte, que como direitos humanos, deve ser global.

Consequentemente, essas relações sociais alteradas indicam uma atenção do Estado ao seu papel de harmonizar e legislar sobre isso. Assim, dialogando interdisciplinarmente com outros meios, a sua posição é mais coesa e coerente com a promoção dos direitos humanos tanto numa esfera particular como social. O Caso Tiffany, de alta repercussão social e midiática recente no país, demonstra que a falta de informação e cientificidade exposta pode gerar comentários de cunho preconceituosos e causar ainda mais estigmas que o grupo já possui. Portanto, ao utilizar a teoria do reconhecimento social demonstrou-se essa acepção social por meio da liberdade, enquanto ao mostrar o Estado ciente do imperativo de conduzir ações afirmativas para a população LGBT, como a tantas outras vulneráveis, legitima o direito a igualdade. Ambos, somados à ideia de identidade, baseada tanto nas teorias de Michel Foucault e Judith Butler, confirmam a dignidade da pessoa humana e a manutenção da dignidade da pessoa humana como um norte ao ordenamento jurídico. 
Reconhecer é o primeiro passo para se conquistar inovações na administração pública, na democracia, ou na viabilização de práticas socais, políticas e financeiras voltadas para tal grupo, ainda marginalizado e que compõe o contexto da modernidade, mas que se lacuna, ainda quanto ao respeito social e o respaldo jurídico integral. Algo tão pessoal, relacionado aos gêneros e sexualidades, que recobra a identidade e a dignidade de cada um, e legitimada pelos seus pares. E aqui, o que se demonstra é que a inclusão pode garantir, a partir de uma noção concreta e científica que não há privilégios ou vantagens, mas sim a demonstração de efetividade da dignidade do atleta, seja transexual ou não.

\section{REFERÊNCIAS}

BARROSO, Luís Roberto. A dignidade da pessoa humana no Direito Constitucional contemporâneo: a construção de um conceito jurídico à luz da jurisprudência mundial. $1^{\text {a }}$ reimpressão. Belo Horizonte: Editora Fórum. 2013.

BENTO, Berenice. É o queer tem pra hoje? Conversando sobre as potencialidades e apropriações da Teoria Queer ao Sul do Equador. Entrevista concedida a Felipe Padilha e Lara Facioli. In. BENTO, Berenice. Transviad@s: gênero, sexualidade e direitos humanos. Salvador: EDUFBA, 2017.

O que é transexualidade. São Paulo: Brasiliense.2008.

BRAGA, Mariana Moron Saes; SCHUMACHER, Aluisio Almeida. Direito e inclusão da pessoa com deficiência: uma análise orientada pela teoria do reconhecimento social de Axel Honneth. Sociedade e Estado, v. 28, n. 2, p. 375-392, 2013.

BUTLER, Judith. Problemas de gênero: feminismo e subversão da identidade. 12. Ed. Rio de Janeiro: Civilização Brasileira, 2016.

CAMARGO, Wagner Xavier; KESSLER, Cláudia Samuel. Além do masculino/feminino: gênero, sexualidade, tecnologia e performance no esporte sob perspectiva crítica. Horizontes Antropológicos, n. 47, p. 191-225, 2017.

CARVALHO, Mario. O "armário trans": entre regimes de visibilidades e luta por reconhecimento. In.

Transexualidades: um olhar multidisciplinar. Maria T. A. D. Coelho e Liliana L. P. Sampaio. Salvador: EDUFBA, 2014.

CASTRO, Cristina Veloso de. As garantias constitucionais das pessoas transexuais. Birigui, SP: Boreal Editora, 2016.

CHARLES, Sébastien; LIPOVETSKY, Gilles. Os tempos hipermodernos. São Paulo: Barcarolla, 2004.

COI. IOC Consensus Meeting on Sex Reassignment and Hyperandrogenism November 2015. Disponível em https://stillmed.olympic.org/Documents/Commissions_PDFfiles/Medical_commission/2015-

11_ioc_consensus_meeting_on_sex_reassignment_and_hyperandrogenism-en.pdf.

FOUCAULT, Michel. História da Sexualidade 1: A vontade de saber. São Paulo: Paz e Terra, 2015.

História da Sexualidade 2: O uso dos prazeres. São Paulo: Paz e Terra, 2014a.

História da Sexualidade 3: O cuidado de si. São Paulo: Paz e Terra, 2014b.

GOELLNER, Silvana Vilodre. Feminismos, mulheres e esportes: questões epistemológicas sobre o fazer historiográfico. Movimento, v. 13, n. 2, p. 173, 2007.

GOELLNER, Silvana Vilodre, et al. Gênero e raça: inclusão no esporte e lazer. 2009. 
HONNETH, Axel. Luta por reconhecimento: a gramática moral dos conflitos sociais (Trad. Luiz Repa). São Paulo: Ed. 34, 2003

O direito da liberdade. São Paulo: Martins Fontes, 2015.

MARQUES, R. F. R. et al. Esporte olímpico e paraolímpico: coincidências, divergências e especificidades numa perspectiva contemporânea. Rev. Bras. Educ. Fís. Esporte, São Paulo, v.23, n.4, p.365-77, out./dez. 2009.

MOEHLECKE, Sabrina. Ação afirmativa: história e debates no brasil. São Paulo: USP/Cadernos de Pesquisa, n.117, novembro/2002.

PEREIRA, Rodrigo da Cunha. A sexualidade vista pelos tribunais. 2. Ed. Belo Horizonte: Del Rey, 2001.

ROTHENBURG, Walther Claudius. Igualdade material e discriminação positiva: o princípio da isonomia. In. Revista Novos Estudos Jurídicos. Volume 13, n. 2. jul - dez/2008.

SARLET, Ingo Wolfgang. As dimensões da dignidade da pessoa humana: construindo uma compreensão jurídico-constitucional necessária e possível. Revista brasileira de direito constitucional, v. 9, n. 1, p. 361-388, 2007.

SARMENTO, Daniel. Dignidade da pessoa humana: conteúdo, trajetórias e metodologia. 2. Ed. Belo Horizonte: Fórum, 2016.

SILVA, Fernanda Duarte Lopes Lucas. Princípio Constitucional da Igualdade. $2^{a}$ edição. Rio de Janeiro: Editora Lumen Juris, 2003.

SOUZA, Jessé. A tolice da inteligência brasileira: ou como o país se deixa manipular pela elite. São Paulo: LeYa, 2015.

UNESCO. Carta Internacional da Educação Física e do Esporte. 2016.

WOLF, Sherry. America'deepest closet: why does the sports world remain fiercely hostile to open participation by LGBT athletes. The Nation, n. 22, p. 29-30, 2011. 